\title{
Reduction of lumbar scoliosis by use of a heel lift to level the sacral base
}

\author{
ROBERT E. IRVIN, DO
}

The relationship between unlevelness of the sacral base and scoliosis is unclear. A method for reducing mild lateral bend of the lumbar spine by use of a heel lift to level the sacral base was tested in adults. Special methods were used to demonstrate the weight-bearing plane of the sacral base and the angle of lateral bend radiographically. The procedure significantly decreased the unlevelness of the sacral base and significantly reduced the angle of lateral bend. The results suggest that an unlevel sacral base contributes to lumbar scoliosis and that use of a heel lift to level the sacral base in mild cases of lumbar scoliosis can be beneficial.

(Key words: idiopathic scoliosis, lumbar scoliosis, pelvic obliquity, sacral base unlevelness, short leg syndrome)

[The sacrum] is the seat of the transverse center of gravity, the keystone of the pelvis, the foundation of the spine. It is closely associated with our greatest abilities and disabilities, with our greatest romances and tragedies, our greatest pleasures and pains.-H. H. Fryette ${ }^{1}$

Scoliosis is not simply a lateral curvature of the spine but rather a three-dimensional deviation of the axial skeleton. ${ }^{2}$ Lateral bend of the spine is a particular aspect of scoliosis. This study tested the hypothesis that leveling a

Dr Irvin is associate professor of general medicine, Department of Manipulative Medicine, College of Osteopathic Medicine of Oklahoma State University, Tulsa.

Reprint request to Robert E. Irvin, DO, Department of Manipulative Medicine, General Practice, College of Osteopathic Medicine of Oklahoma State University, 1111 W 17th St, Tulsa, OK 74107. mildly unleveled sacral base by the use of a heel lift is followed by a significant decrease in lateral bend of the lumbar spine. ${ }^{3}$

The view that a level pelvis ${ }^{4}$ and a vertical lumbar spine constitute optimal posture is attractive. Commonly, however, the pelvis is not quite level and the lumbar spine is not quite vertically aligned (Fig 1 ).

A heel lift is an orthosis that can be applied to reduce pelvic unlevelness. The Greek root for orthosis is orthos, meaning "standing up straight" and "being correct." 5 Lifts have long been used to raise the lower side of the pelvis as treatment for malady of the back. ${ }^{6,7}$

Patriquin ${ }^{6}$ and Beal ${ }^{8}$ observed a lack of objective evidence of the results of lift therapy. Patriquin $^{6}$ found it surprising that authors of articles on lift therapy do not offer studies of results. Typically, reports are anecdotal. For example, in 1863 John Hilton ${ }^{9}$ noted:

Thus I have seen many patients wearing spinal supports, in order to correct a lateral [spinal] curvature, when the deformity might have, and has been subsequently, corrected by placing within the shoe or boot a piece of cork thick enough to compensate for the shortness of the less well developed limb.

The fact that this is an old question means that there has been sufficient time for studies to have occurred. Lack of report of study is due, in part, to the fact that there are controversial and technical difficulties to lift therapy.

There is controversy as to whether and to what extent unlevelness of the pelvis relates either to lumbar scoliosis or low back pain. ${ }^{1,2,4,6-8,10-23}$ Part of this controversy is due to uncertainty about how to measure the pelvic level with greatest validity. References

(continued on page 37) 


\section{A BRIGHT IDEA... IN MLD TO MODERATE HYPERTENSION}

180-mg Calan SR...once-daily, single-agent therapy

- Efficacy proven comparable to 240 mg'

- 24-hour control with once-daily dosing *

- Low-dose, well-tolerated therapy A more economical choice ${ }^{*}$

"Total daily dosages above $240 \mathrm{mg}$ should be administered in divided doses. Calan SR should be administered with food.

Constipation. which is easlly managed in most patients, is the most commonly reported side effect of Calan SR

'Price comparison versus 240-mg Calan SR.

Please see next page of this advertisement for references and a brief summary of prescribing information.

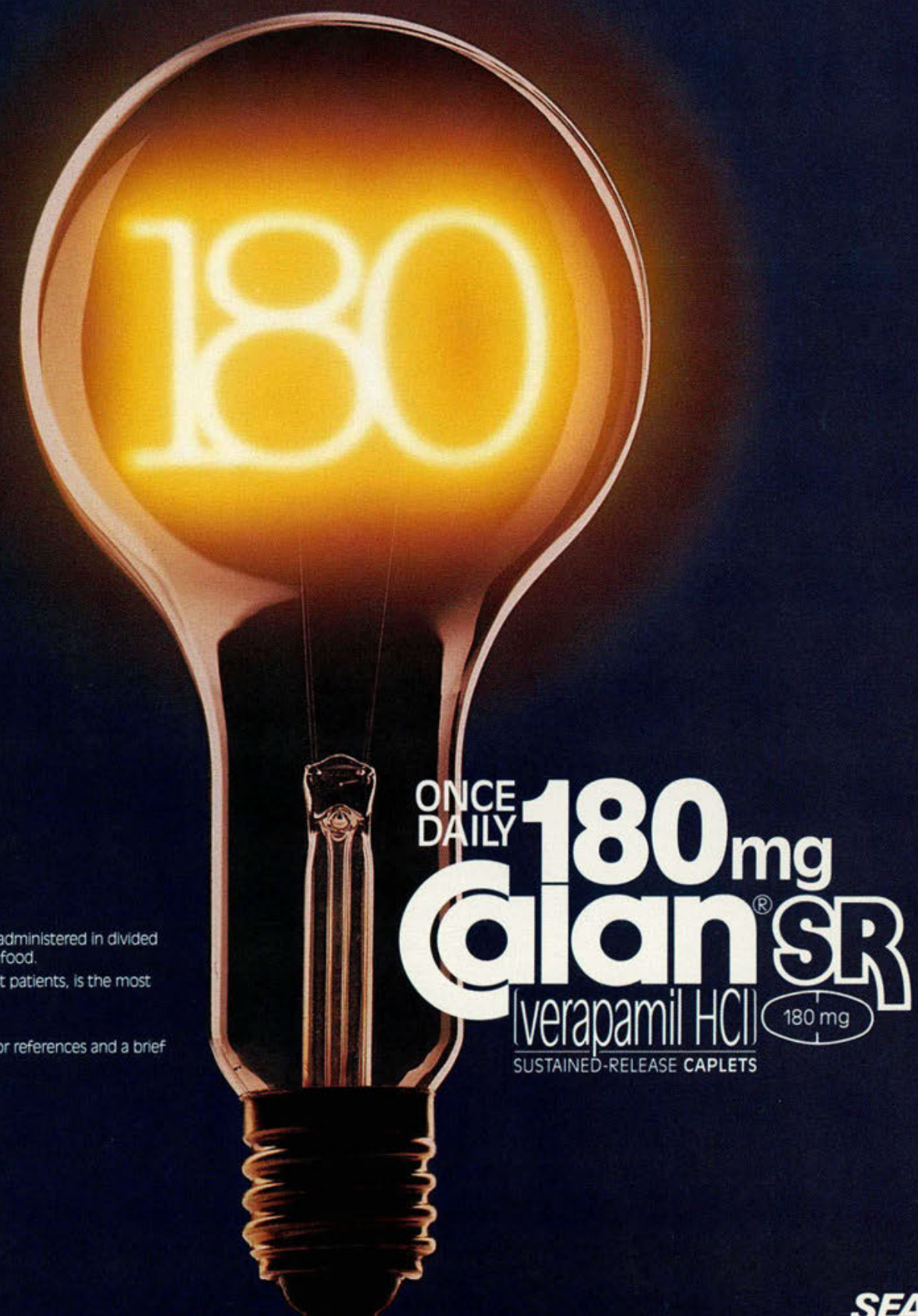




\section{Consistent with 1988 JNC recommendation...}

\section{The 1988 report of the Joint National Committee on Detection, Evaluation, and Treatment of High Blood Pressure recommends that blood pressure be controlled "...with the fewest drugs at their lowest dose...."}

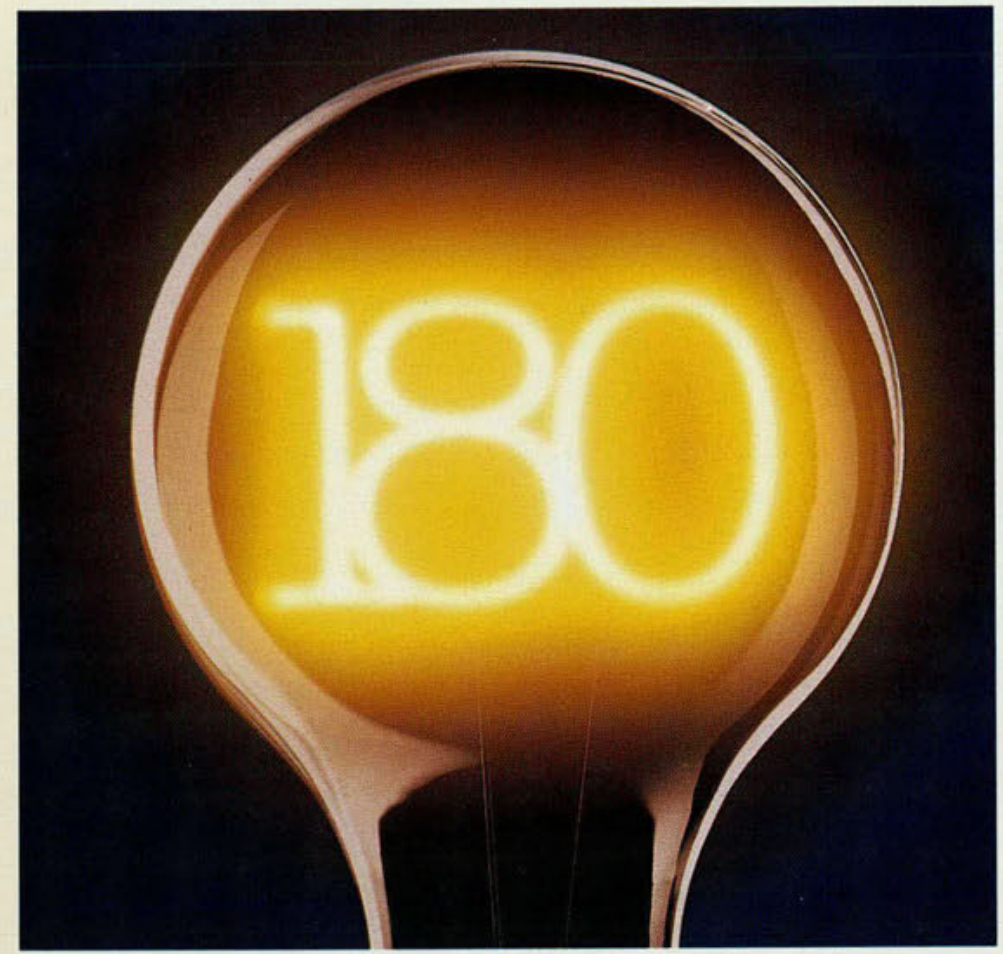

\author{
When you want high \\ single-agent efficacy in a \\ lower dose, prescribe...
}

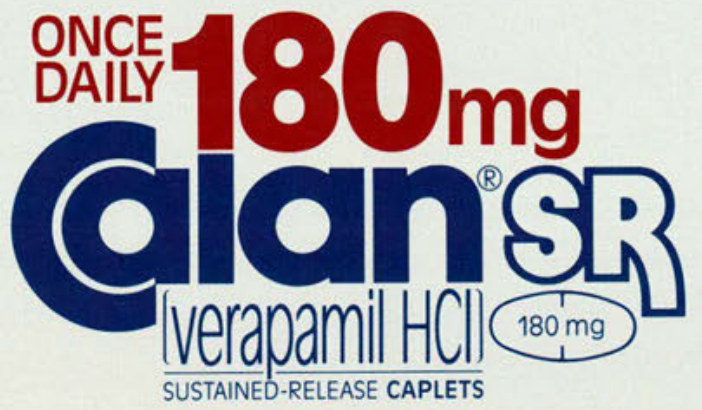

A BRIGHT IDEA
in verapamil SR therapy

References:

1. Data on file, G.D. Searle \& Co. 2. 1988 Joint National Committee:

The 1988 report of the Joint National Committee on Detection,

Evaluation, and Treatment of High Blood Pressure. Arch Intern Med 1988;148:1023-1038

\section{BRIEF SUMMARY}

Contraindications: Severe LV dysfunction (see Warnings), hypotension (systolic pressure $<90 \mathrm{~mm} \mathrm{Hg}$ ) or cardiogenic shock, sick sinus syndrome (if no pacemaker is present), 2nd- or 3rd-degree AV block (if no pacemaker is present), atrial flutter/fibrillation with an accessory bypass tract (eg, WPW of LGL syndromes), hypersensitivity to verapamil.

Warnings: Verapamil should be avoided in patients with severe LV dysfunction (eg, ejection fraction $<30 \%$ ) or moderate to severe symptoms of cardiac failure and in patients with any degree of ventricular dysfunction if they are receiving a beta-blocker. Control milder heart failure with optimum digitalization and/or diuretics before Calan SR is used. Verapamil may occasionally produce hypotension. Elevations of liver enzymes have been reported. Several cases have been demonstrated to be produced by verapamil. Periodic monitoring of liver function in patients on verapamil is prudent. Some patients with paroxysmal and/or chronic atrial flutter/fibrillation and an accessory AV pathway (eg, WPW or LGL syndromes) have developed an increased antegrade conduction across the accessory pathway bypassing the AV node, producing a very rapid ventricular response or ventricular fibrillation after receiving I.V. verapamil (or digitalis). Because of this risk, oral verapamil is contraindicated in such patients. AV block may occur (2nd-and 3rd-degree, $0.8 \%$ ). Development of marked 1st-degree block or progression to 2nd- or 3rddegree block requires reduction in dosage or, rarely, discontinuation and institution of appropriate therapy. Sinus bradycardia, 2nd-degree AV block, sinus arrest, pulmonary edema and/or severe hypotension were seen in some critically ill patients with hypertrophic cardiomyopathy who were treated with verapamil.

Precautions: Verapamil should be given cautiously to patients with impaired hepatic function (in severe dysfunction use about $30 \%$ of the normal dose) or impaired renal function, and patients should be monitored for abnormal prolongation of the PR interval or other signs of overdosage. Verapamil may decrease neuromuscular transmission in patients with Duchenne's muscular dystrophy and may prolong recovery from the neuromuscular blocking agent vecuronium. It may be necessary to decrease verapamil dosage in patients with attenuated neuromuscular transmission. Combined therapy with beta-adrenergic blockers and verapamil may result in additive negative effects on heart rate, atrioventricular conduction and/or cardiac contractility; there have been reports of excessive bradycardia and AV block, including complete heart block. The risks of such combined therapy may outweigh the benefits. The combination should be used only with caution and close monitoring. Decreased metoprolol clearance may occur with combined use. Chronic verapamil treatment can increase serum digoxin levels by $50 \%$ to $75 \%$ during the first week of therapy, which can result in digitalis toxicity. In patients with hepatic cirrhosis, verapamil may reduce total body clearance and extrarenal clearance of digitoxin. The digoxin dose should be reduced when verapamil is given, and the patient carefully monitored. Verapamil will usually have an additive effect in patients receiving blood-pressure-lowering agents. Disopyramide should not be given within 48 hours before or 24 hours after verapamil administration.
Concomitant use of flecainide and verapamil may have additive effects on myocardial contractility, $\mathrm{AV}$ conduction, and repolarization. Combined verapamil and quinidine therapy in patients with hypertrophic cardiomyopathy should be avoided, since significant hypotension may result. Concomitant use of lithium and verapamil may result in a lowering of serum lithium levels or increased sensitivity to lithium. Patients receiving both drugs must be monitored carefully. Verapamil may increase carbamazepine concentrations during combined use. Rifampin may reduce verapamil bioavailability. Phenobarbital may increase verapamil clearance. Verapamil may increase serum levels of cyclosporin. Concomitant use of inhalation anesthetics and calcium antagonists needs careful titration to avoid excessive cardiovascular depression. Verapamil may potentiate the activity of neuromuscular blocking agents (curare-like and depolarizing); dosage reduction may be required. Adequate animal carcinogenicity studies have not been performed. One study in rats did not suggest a tumorigenic potential, and verapamil was not mutagenic in the Ames test. Pregnancy Category C. There are no adequate and well-controlled studies in pregnant women. This drug should be used during pregnancy, labor, and delivery only if clearly needed. Verapamil is excreted in breast milk; therefore, nursing should be discontinued during verapamil use.

Adverse Reactions: Constipation (7.3\%), dizziness (3.3\%), nausea (2.7\%), hypotension (2.5\%), headache $(2.2 \%)$, edema $(1.9 \%)$, CHF, pulmonary edema $(1.8 \%)$, fatigue $(1.7 \%)$, dyspnea $(1.4 \%)$, bradycardia: $\operatorname{HR}<50 / \mathrm{min}(1.4 \%)$, AV block: total $1^{\circ}, 2^{\circ}, 3^{\circ}(1.2 \%), 2^{\circ}$ and $3^{\circ}(0.8 \%)$, rash $(1.2 \%)$, flushing $(0.6 \%)$, elevated liver enzymes. The following reactions, reported in $1.0 \%$ or less of patients, occurred under conditions where a causal relationship is uncertain: angina pectoris, atrioventricular dissociation, chest pain, claudication, myocardial infarction, palpitations, purpura (vasculitis), syncope, diarrhea, dry mouth, gastrointestinal distress, gingival hyperplasia, ecchymosis or bruising, cerebrovascular accident, confusion, equilibrium disorders, insomnia, muscle cramps, paresthesia, psychotic symptoms, shakiness, somnolence, arthralgia and rash, exanthema, hair loss, hyperkeratosis, macules, sweating, urticaria, Stevens-Johnson syndrome, erythema multiforme, blurred vision, gynecomastia, increased urination, spotty menstruation, impotence. $12 / 21 / 89 \cdot P 90-W 198 \mathrm{~V}$

SEARLE $\begin{array}{ll}\text { G.D. Searle \& Co. } \\ \text { Box } 5110, \text { Chicago, } 1 L 60680\end{array}$

Address medical inquiries to:

G.D. Searle \& Co.

Medical \& Scientific

Information Department

4901 Searle Parkway

Skokie, IL 60077 


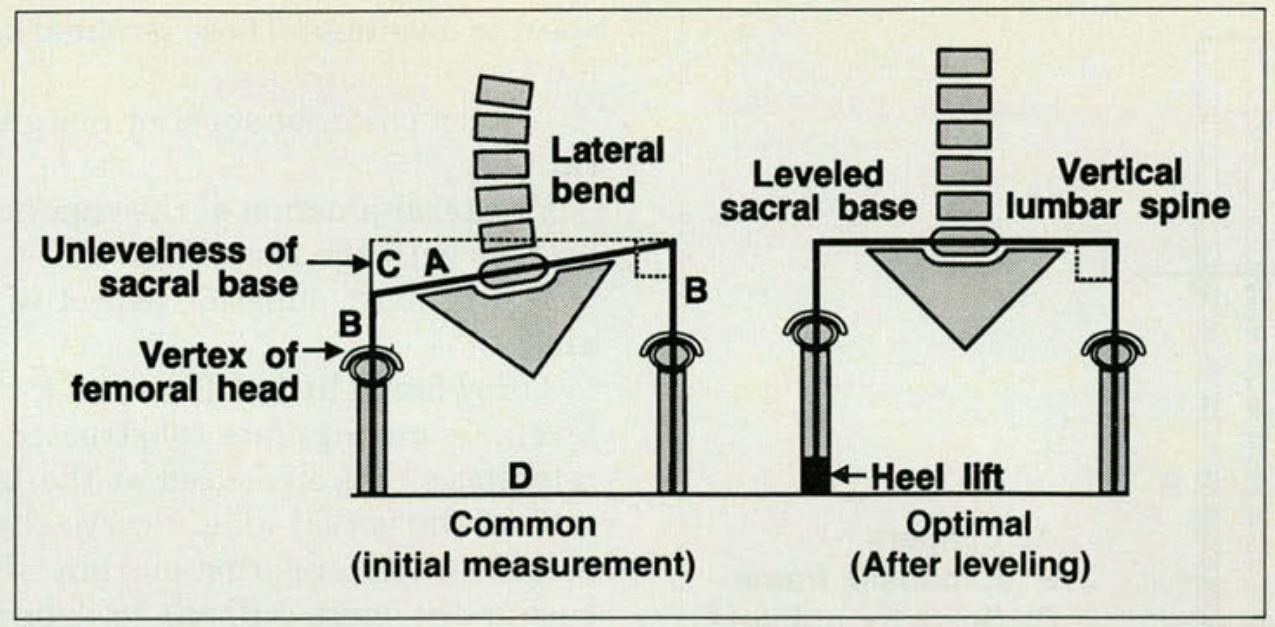

Figure 1. Diagrams of lumbosacral configuration before and after leveling of the sacral base. Left: Configuration of the lumbopelvis that commonly occurs. Line A: parallel to sacral base; Line B: line segments extended vertically through the vertex of each femoral head to intersect Line A; Line $C$ : measured difference between Lines $B$, recorded as millimeters of unlevelness of the sacral base with respect to the femoral heads. Line D: level margin of film. Right: Diagrammatic representation of hypothesis that placement of a heel lift of sufficient thickness can result in a level sacral base and a more vertical lumbar spine.

used for measuring the pelvic level vary, including comparison of leg lengths while supine, heights of the iliac crests while standing, and unlevelness of the sacral base by postural radiography. In view of the lack of studies, one's choice of references is arbitrary at present.

Cailliet ${ }^{10}$ stated that to determine pelvic level involves evaluating differences in leg lengths. He reasoned that the legs influence the level of the pelvis through their upright support. Schwab ${ }^{11}$ classified etiologic factors for adults with disparity of leg lengths $>0.5$ $\mathrm{cm}$, citing etiologic factors for short leg as unequal development in $53 \%$, altered growth due to fracture or epiphysitis in $27 \%$, and congenital deformation of the sacrum or femurs in $5.5 \%$. Correction of pelvic unlevelness due solely to inequality of leg lengths can be by a heel lift, shortening the long leg, or lengthening of the short leg. ${ }^{12}$

Grundy and Roberts ${ }^{4}$ tested the hypothesis that unequal leg length is an important etiologic factor in pain of the low back. In this casecontrol epidemiologic study, patients with history of low back pain were compared with a control group without history of low back pain. Variables used for measuring leg lengths in- cluded the anterior superior iliac spines, posterior superior iliac spines, and patellas. Measurement was by the use of a locating jig (Fig 2 ), adapted from an instrument originally used to measure the length of the lower part of the leg for boots. No significant relation was found between disparity of leg lengths (within the percentage variation of the variables measured) and the history of low back pain. As a result, Grundy and Roberts doubted short leg was associated with chronic back pain. Their study, however, did not rule out the possibility that the pelvic level is best measured by reference(s) other than leg lengths, and that such hypothetical reference(s) relates more directly to lumbopelvic mechanics than does disparity of leg lengths.

The method described by Cailliet ${ }^{10}$ for measurement of pelvic level was physical examination of three references: (1) the height of the iliac crests; (2) "dimples" of the posterior superior iliac spines; and (3) angle of ascent of the lumbar spine from the sacrum.

He stated that measurement of the pelvic level is accurate to within $1 / 4$ inch, and that this accuracy is sufficient. Because the vertebral column rests and is vertically dependent upon a level pelvis (Fig 1), a superincumbent 


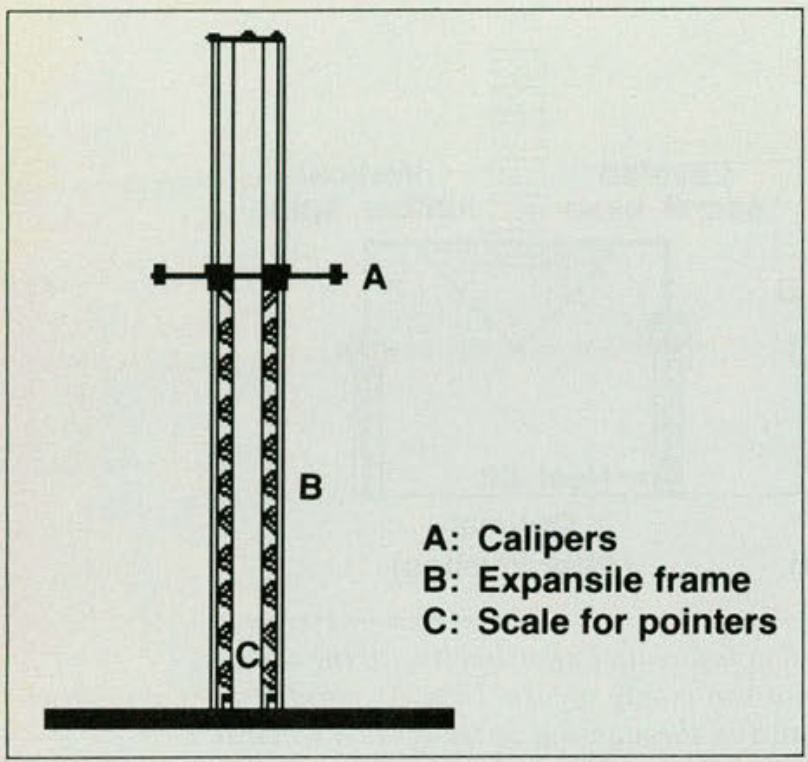

Figure 2. Locating jig for measurement of inequality of leg lengths. (From Grundy and Roberts. ${ }^{4}$ )

scoliosis can result if the sacral base is oblique. ${ }^{14}$ Making the pelvis more level by the use of a heel lift can reduce this scoliosis. According to Cailliet, however, this relation is limited in that a difference in leg lengths of less than $3 / 4$ inch does not have a deleterious effect on the scoliosis and thus rarely needs correction by lift. This limit is questionable, as one could ask why reduction of pelvic obliquity to $3 / 4$ inch is beneficial, and further reduction is not. Again, it is possible that unlevelness of the pelvis measured by a reference other than those just listed relates more directly to scoliosis.

Kraus $^{14}$ recommended that measurement of postural indices be done by radiography because it is more accurate than physical examination. Greenman ${ }^{15}$ stated that the pelvic level (measured radiographically) and lumbopelvic mechanics relate more directly to levelness of the weight-bearing surface of the sacral base than they do to disparity of leg lengths. Various anatomic references have been used for radiographic delineation of the sacral base. A reason for this variety is the difficulty in identifying radiographically the anatomic sacral base. Tilley ${ }^{16}$ described radiographic delineation of the sacral base, and tested three different landmarks (Fig 3, labels A, B, and C) for agreement, each with the other, with re- spect to levelness. These landmarks are as follows:

A. most posterior superior margin of the sacral base;

B. lateral junction of the superior articular process with the sacral ala; and

C. the most superior aspect of the sacral alae.

Tilley found little difference $(P<.01)$ in unlevelness among lines constructed from these references and measured at the lateral margins of the sacral alae. Practically, the most posterior and superior margin of the sacral base is the most difficult to delineate on the film. Nonetheless, both Tilley ${ }^{16}$ and Greenman ${ }^{15}$ preferred this sacral parameter partly because of its proximity to the sacral base.

A difference between Tilley's study and the current one is that the unlevelness of the line delineated (by any reference) was measured with respect to the lateral position of the margins of the sacral alae by Tilley, rather than at the lateral position of the apex of the femoral heads. For a given degree of tilt, the unlevelness increases the further from the point of pivot one measures. It is possible that insignificant differences in unlevelness measured at the alae are significant where measured relative to the more lateral position of the femoral heads.

Greenman ${ }^{15}$ recommended the use of a heel lift to level the weight-bearing plane of the sacral base to normalize the lumbopelvic mechanics. Although he did not use lift therapy to influence lumbar scoliosis, he associated unlevelness of the sacral base $\geqslant 4 \mathrm{~mm}$ with a positive history of low back pain, and reported that reduction of pain reliably followed the use of a heel lift to level the sacral base. This association points to the possibility that scoliosis, as an aspect of impaired lumbopelvic mechanics, also relates more directly to unlevelness of the sacral base than does inequality of leg lengths. Importantly, for a normal lumbopelvic spine, none of the bony configurations listed here bear the primary weight of the vertebral column. A reference for the primary weight-bearing plane of the sacral base is needed if we are to manipulate the pelvic level accurately. 

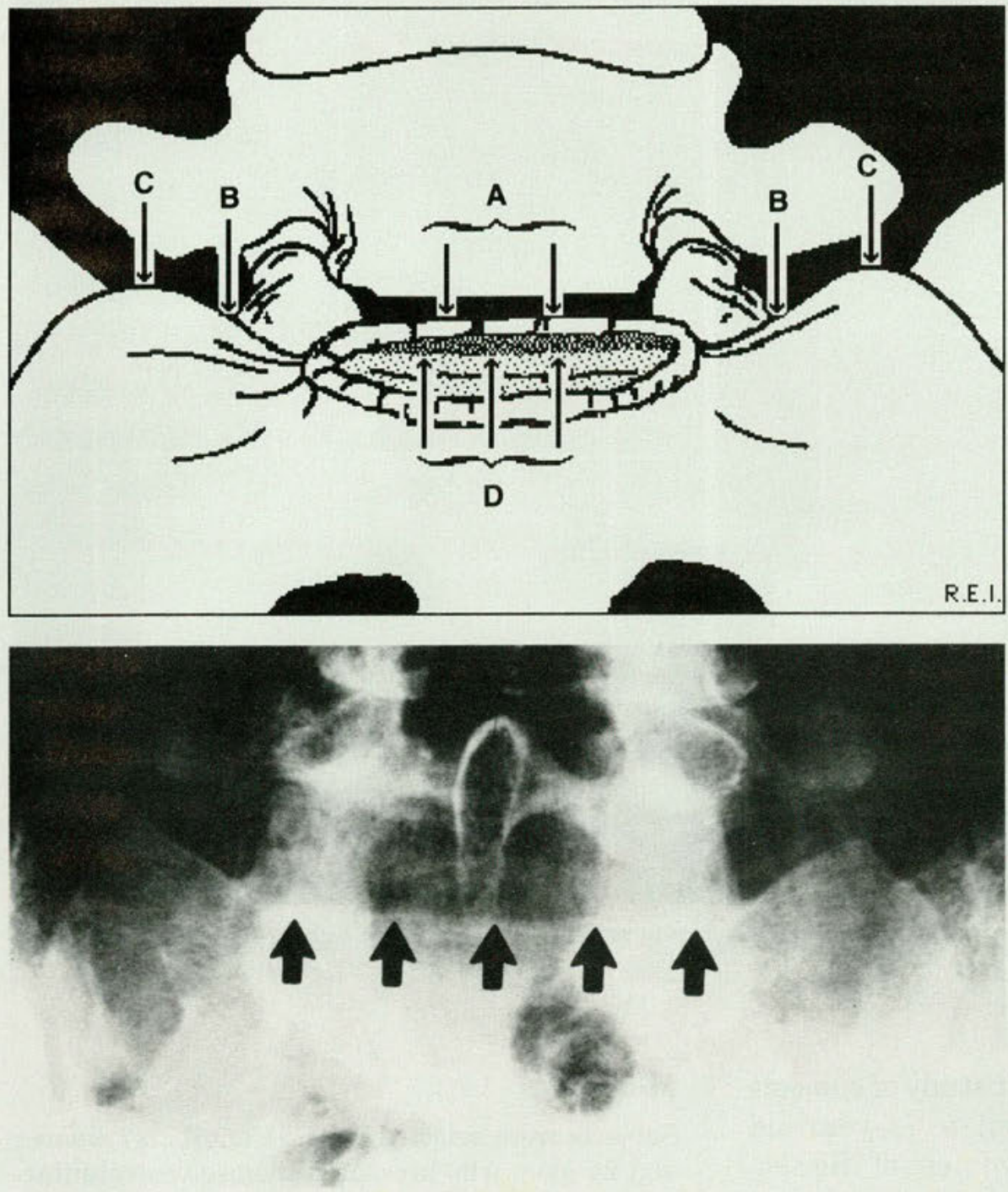

Figure 3. Bony references for delineation of the sacral base. Those used by previous investigators ${ }^{15}$ are (A) most posterior superior margin of the sacral base; (B) lateral junction of the superior articular process with the sacral ala; and (C) most superior aspect of the sacral alae. The radiopaque stratum of eburnation (D) was used for this study.

Figure 4. Radiograph demonstrating the radiopaque stratum of eburnation used to delineate the weight-bearing plane of the sacral base.
As a refinement toward radiographic delineation of the weight-bearing plane of the sacral base, the reference used for this study (Fig 3, label D, and Fig 4) was the white line of increased bone density (eburnation) that transversely spans the sacral base, seen slightly inferior to the most posterior margin of the sacral promontory. Eburnation, also referred to as bone sclerosis, is an increase in the density of the bone so that its radiographic appearance is whiter than normal, according to Meschan $^{24}$ and verbal communication in 1980 with F. Wilkins, DO. The deposition of bone is proportional to its compressional load, ${ }^{25}$ in this case, of the superincumbent spinal column. From the anteroposterior view, this plane of eburnation, viewed somewhat edge-on, appears as a white line. This physiologic line was chosen over other bony references because it is:

1. an observable line one can delineate radiographically, rather than an imaginary line constructed between two points of reference;

2. more easily delineated than is the less radiopaque posterior superior margin of the sacral base; and

3 . considered to reflect more directly the principal plane of weight bearing than do the other references that result less from function

By use of this line, the effect of leveling of the weight-bearing plane of the sacral base on scoliosis of the lumbar spine can be measured. 

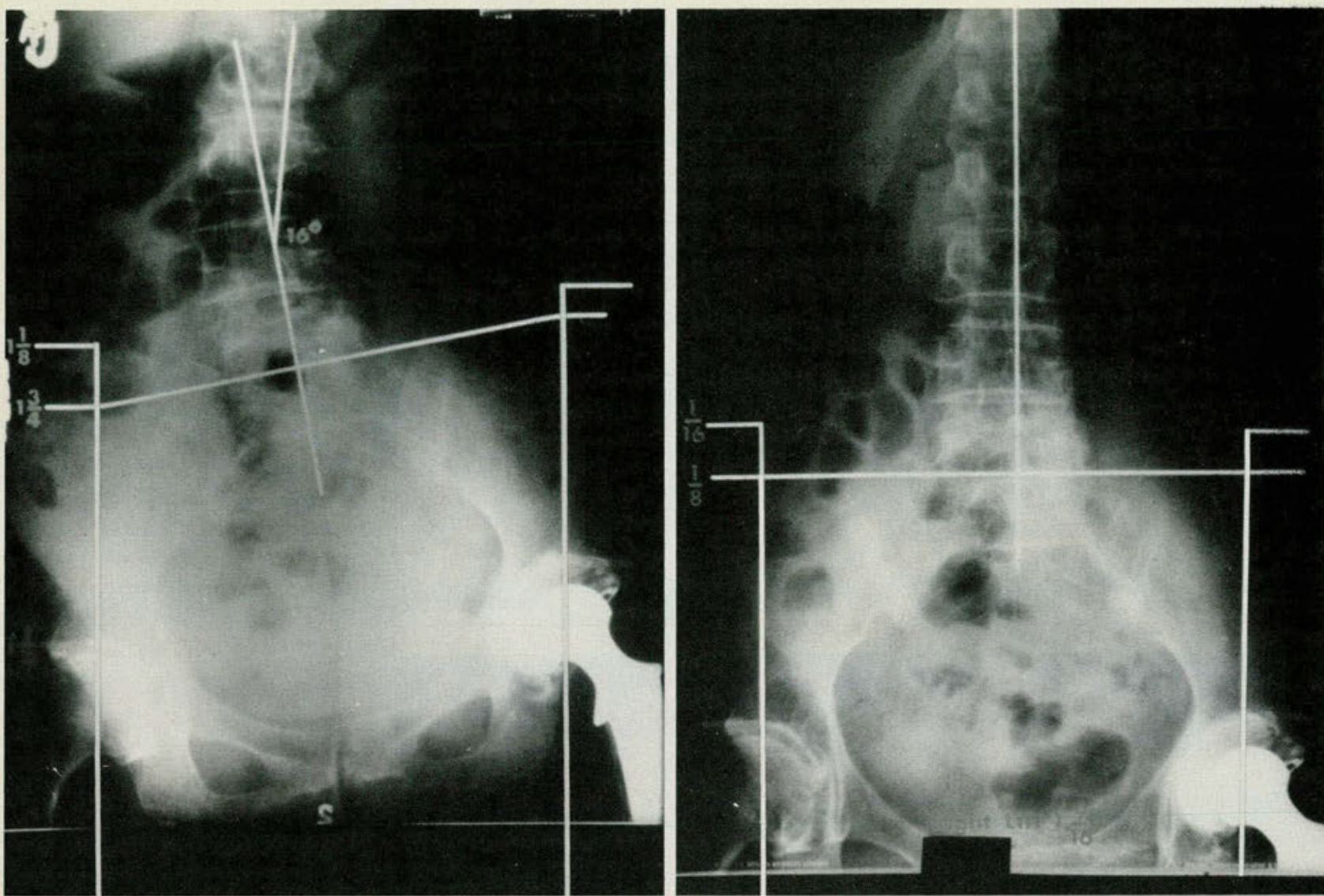

Figure 5. Anteroposterior views of patient in upright posture in preliminary case study before (left) and after (right) intervention.

Preliminary to the current study of subjects with unlevelness $<19 \mathrm{~mm}$, a 71 -year-old woman was seen with unlevelness of the sacral base of $45 \mathrm{~mm}$ with respect to the lateral location of the femoral heads, and 16 degrees of lateral bend in the lumbar spine (Fig 5, left). Forty-four weeks after the initiation of treatment, and 2 weeks after the final increase of thickness of the heel lift, the patient underwent radiography with a $40-\mathrm{mm}$ lift in place (Fig 5, right). The sacral base was within 3 $\mathrm{mm}$ of level, and lateral bend in the lumbar spine was absent. This degree of spinal straightening was surprising, given the patient's age and degree of deformity. Although this result agreed with the assertion that scoliosis and unlevelness of the sacral base are interrelated, the limits of this relationship were not clear. This current study was aimed to test the lower limit of this relationship.

\section{Method}

Subjects were selected from 51 adults, 27 women and 24 men, who presented themselves voluntarily from September 1981 through December 1985 to a clinic that emphasized treatment of musculoskeletal disorders. Given that idiopathic scoliosis in adults is known either to remain unchanged (static) or increase with passage of time (progressive) ${ }^{2}$ study subjects served as their own control. Subjects who evidenced congenital anomalies or degenerative changes in their lumbopelvic radiographs were excluded. This population was further restricted to those who showed both sacral base unlevelness that ranged from 2 to $17 \mathrm{~mm}$, and lateral bend in the lumbar spine that ranged from 2 to 19 degrees $(\mathrm{N}=42)$. This range of unlevelness was chosen as it is less than the amount of inequality of leg lengths stated by Cailliet ${ }^{13}$ to be significant in the etiology of scoliosis. In this way, the effect of leveling a mildly unlevel pelvis using the sacral base as reference can be tested. Of the original population, $98 \%$ had unlevelness $\geqslant 2 \mathrm{~mm}$. 
On two occasions and for each subject, an anteroposterior film of the lumbar spine and pelvis was taken with the subject upright and weight-bearing. This radiographic postural study ${ }^{14,20,26}$ was initially performed with the patient shoeless. The feet were parallel, positioned directly beneath the acetabula, with the buttocks in direct contact with the plane of the cassette. This technique minimized pelvic rotation with respect to the vertical axis. The participant's arms were folded across the chest so as to remove them from the visualized field.

The radiographic film was Du Pont Cronex 7 . This rectangular film was supported on a base horizontality controlled via a bubble level. A Quanta III intensifying screen was used with constant kilovoltage $(\mathrm{kVp})$ technique. The focal-spot-to-film distance was 40 inches, with the ray centered at the level of L-5. For each subject, approximately $0.12 \mathrm{rad}$ was delivered to the midplane at $80 \mathrm{kVp}$ and $40 \mathrm{~mA}$.

By the following method, the weight-bearing plane of the sacral base was delineated and its unlevelness measured relative to the lateral position of the femoral heads. The developed film was supported in a film holder with its lower margin level (Fig 1, left, line D). A line (A) was drawn on the film parallel to the transverse stratum of eburnation (Fig 3, label D, and Fig 4) within the sacral base. This line was extended laterally to intersect the vertical line segments B, drawn from the lower margin of the film and extended vertically through the vertex (or highest point) of each femoral head to intersect line A. The vertical spans from the right and left points of intersection to the lower margins of the film were compared and the difference (line segment $\mathrm{C}$ ) was recorded as millimeters of unlevelness of the sacral base with respect to the lateral position of the femoral heads.

To measure the angle of lateral bend $(\varnothing)$ of the lumbar spine (Fig 6), a line was drawn through the most superior and inferior aspect of the spinous process and extended so as to connect the greatest number of aligned spinous processes of the lumbar spine. A second line, so drawn, connected the juxtaposed group of aligned spinous processes. This second line was extended to intersect with the first line, and formed the angle of lateral bend. A few subjects had more than one bend along the lumbar spine. When more than one angle was present, the angle with the greatest degree was recorded.

Serially, subjects wore a lift of graduated thickness inside their shoe beneath the calcaneus. The lift was composed of cork not significantly compressible under the stress of normal weight. Every 2

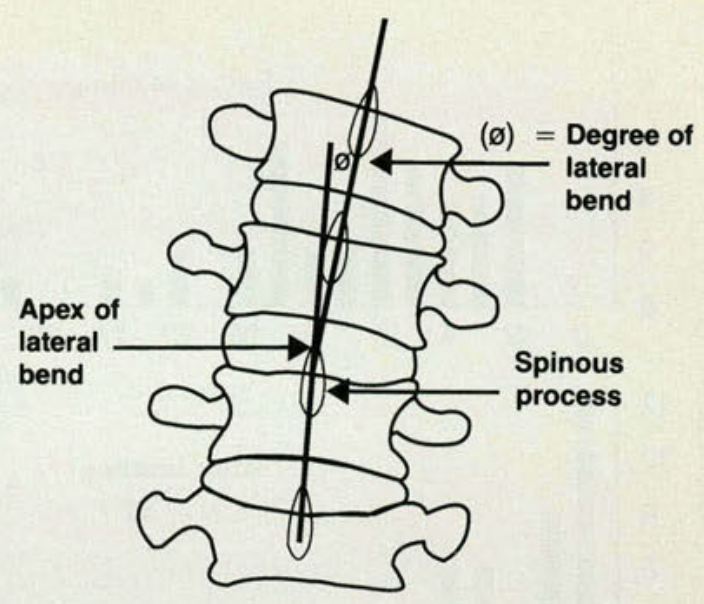

Figure 6. Diagram of anteroposterior view showing measurement of angle of lateral bend in lumbar spine with a measurable degree of lateral bend $(\emptyset)$.

weeks, the heel lift was augmented in thickness by $1.6 \mathrm{~mm}$. Also every 2 weeks, the soft tissues and joints of the subjects were examined for restriction from normal freedom of motion. Where resistance to normal motion was identified, ${ }^{27,28}$ the restricted soft and articular tissues were taken through the physiologic range of motion ${ }^{29,30}$ to reduce resistance to possible change of orientation of the vertebrae. This activity was comfortable for the subjects and was performed for an average of 15 minutes per session. This cycle was repeated until the thickness of the lift was equal to the number of millimeters of sacral unlevelness initially measured.

Two weeks after the final increase in lift thickness, all subjects underwent radiography a second time, with the lift inside shoes routinely worn by the subjects. From this final film, the unlevelness of the sacral base and the lateral bend in the lumbar spine were measured.

In preliminary study of this method, several days after the incorporation of the heel lift, subjects occasionally reported a temporary increase in musculoskeletal discomfort in one or more regions of the musculoskeletal system. These reports might or might not involve the same regions that initially had discomfort. Such discomfort occurred more commonly if the thickness of the initial lift exceeded $3 \mathrm{~mm}$, if frequency of lift augmentation was greater than every 2 weeks, or if the change in thickness of the lift exceeded $1.6 \mathrm{~mm}$.

Routinely, the increase of discomfort lessened 


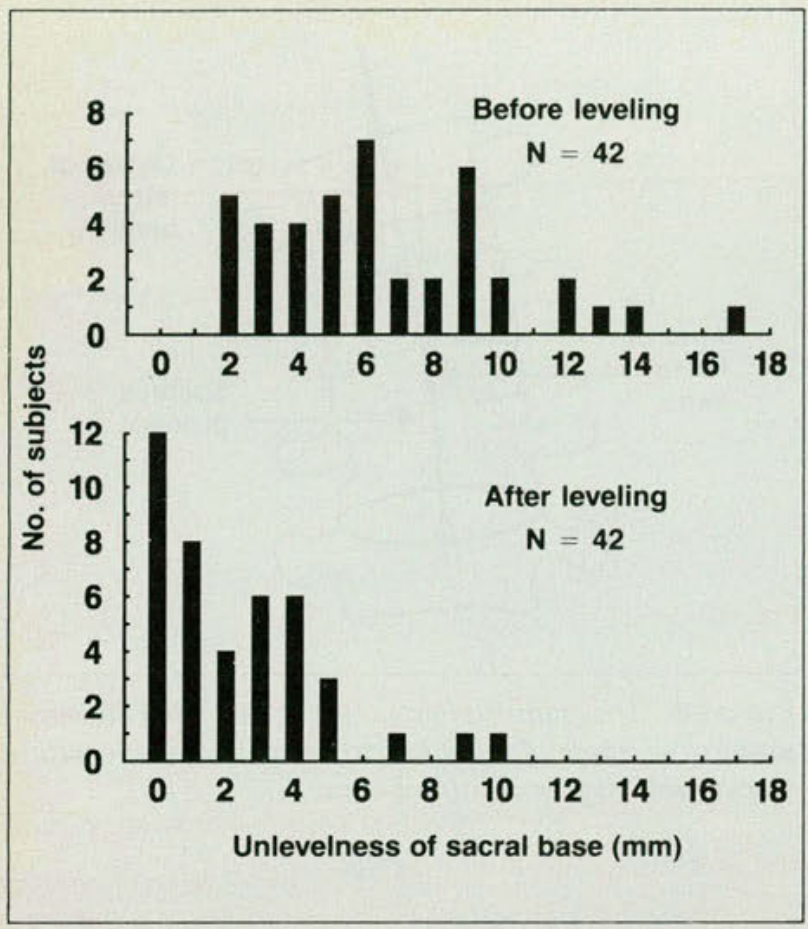

Figure 7. Effect of incorporation of a heel lift on unlevelness of the sacral base.

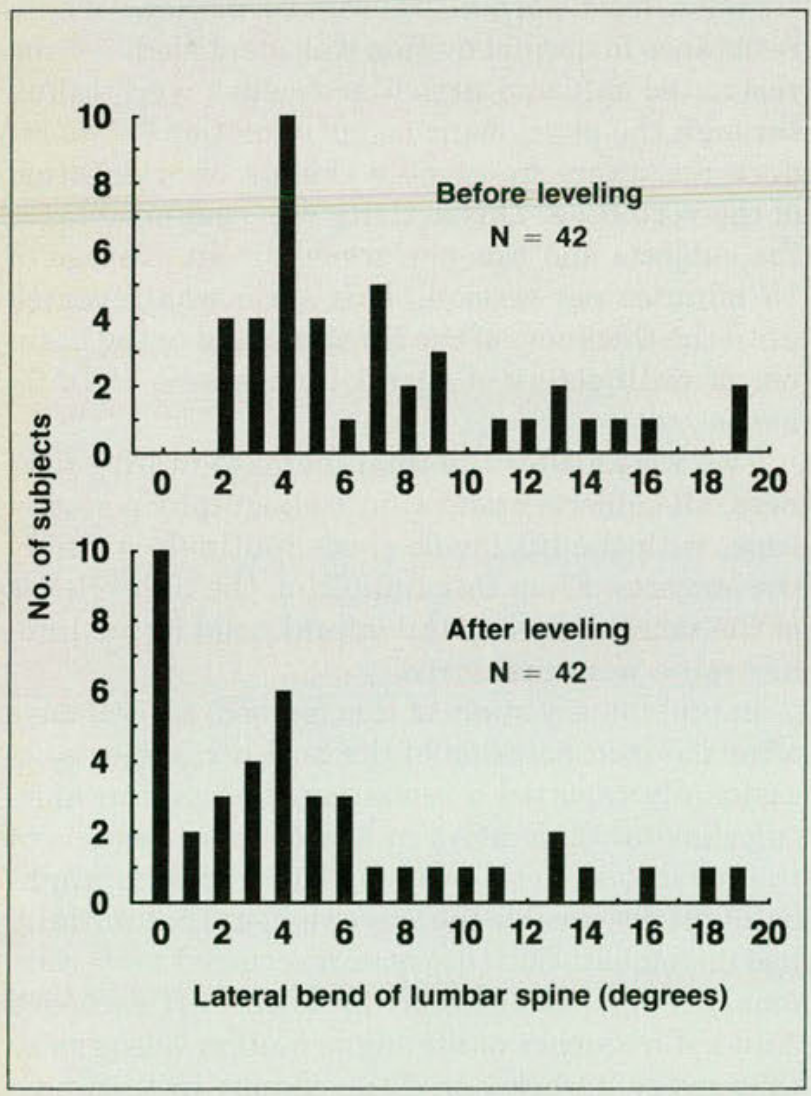

Figure 8. Effect of leveling of the sacral base on lateral bend in the lumbar spine. within a week to 10 days after onset. For this study, the increment of augmentation was restricted to $1.6 \mathrm{~mm}(1 / 16 \mathrm{in})$ every 2 weeks, to minimize discomfort secondary to the incorporation of a lift.

If the thickness of the lift exceeded the available space within the shoe, the excess lift was either added to the outer heel (by an orthotist), or the vertical extent of the contralateral heel was reduced. For subjects with an augmentation of the heel $>8 \mathrm{~mm}$, the thickness of the sole also was augmented so that the difference between the thickness of the heel and sole did not exceed $8 \mathrm{~mm}$. This increase in thickness of the sole was intended to minimize the difference in pitch between the right and left shoes and thereby avoid secondary torsion of the pelvis about the vertical axis.

After intervention, the degree of reduction of lateral bend in the lumbar spine was calculated as the difference between the initial and postintervention angles. This method was used over that of Cobb or Ferguson ${ }^{30}$ for three reasons:

1. except for nonsymmetry of the spinous process, the line would have the same direction as the cephalad-caudad axis of the vertebra;

2. significant change in the lateral bend so measured has clinical meaning; and

3. two rather than four lines (Cobb) are used for delineation.

Subjects were tested before and after intervention. Data for the effect of a heel lift on unlevelness of the sacral base and on reduction of lateral bend of the lumbar spine were analyzed with paired $t$ tests.

\section{Results}

Initially, unlevelness of the sacral base ranged from 2 to $17 \mathrm{~mm}$, with a mean of $6.7 \pm 1.0$ $\mathrm{mm}$ (Fig 7). By completion of the study this unlevelness was significantly decreased to 2.6 $\pm 0.4 \mathrm{~mm}$ (Fig 7) $t=6.6, P<.001$ ). Undercorrection was far more frequent than overcorrection.

Prior to the incorporation of the heel lift, the angle of lateral bend ranged from 2 to 19 degrees, with an average of 7.5 degrees. After leveling of the sacral base, the angle was significantly reduced to a mean of $5.3 \pm 0.8 \mathrm{de}$ grees (Fig 8); $t=3.3, P<.01$ ). For those with residual unlevelness of the sacral base, further leveling yielded further reduction of lateral bend (data not shown).

On a case-by-case basis, agreement between 
the attitude of the line of eburnation compared with that of the aforementioned anatomic references varied considerably.

Approximately one third of the patients reported a brief (1 to 7 day) crescendo of discomfort as the final $20 \%$ of the unlevelness was corrected. These discomforts were myalgia, occasional slight nausea, and malaise, and occurred more commonly in those subjects with greater initial scoliosis.

\section{Discussion}

These findings provide the basis for a number of conclusions and questions.

No previous study has established causality for the majority of scoliosis. Although the present experiment did not induce scoliosis, the observation that lumbar scoliosis $<20$ degrees is reduced after leveling the sacral base strongly suggests a structure/function coupling between even mild unlevelness of the sacral base and spinal scoliosis.

These findings agree with the recommendation of Greenman ${ }^{15}$ that a heel lift be used to level the weight-bearing plane of the sacral base in order to normalize lumbopelvic mechanics. The results also demonstrate a structure/ function relationship between unlevelness of the sacral base and the degree of lumbar scoliosis.

A reference is described for radiographic delineation of the primary weight-bearing plane of the sacral base. This reference, a radiopaque line of eburnation, is thought to be formed as a physiologic response to the stress of weight bearing of the superincumbent spine. Unlevelness of the sacral base, so delineated, relates more directly to scoliosis than does pelvic unlevelness measured by physical examination of iliac crests, the posterior superior iliac spine, or angle of ascent of spine from the sacrum. On a case-by-case basis, agreement between the attitude of the line of eburnation, compared with that of anatomic references used by other investigators to delineate the sacral base, varied considerably. It is possible that another reference for the sacral base relates even more directly to the degree of scoliosis.

The margin of error of unlevelness of the sacral base measured radiographically is 1.0 to $1.5 \mathrm{~mm} \cdot{ }^{15}$ For most subjects, the measurement of the unlevelness of the transverse plane of the sacral base was easily made. In approximately $20 \%$ of subjects, clear delineation of this reference plane was somewhat difficult. Nonetheless, in all subjects the lateral tilt of the sacral base was measurable.

Rotation of the vertebral body about the vertical axis can alter the angle of lateral bend as measured in this study. For subjects with less than 20 degrees of lateral bend, such rotation is minimal and is not a significant factor contributing to this angle.

\section{Risks}

There is risk of experiencing a brief crescendo of discomfort as the final $20 \%$ of unlevelness is corrected. Both central and peripheral discomfort can be a feature of reduction of scoliosis by lift therapy. A possible cause of this discomfort is soft tissue resistance to spinal straightening. The only contraindication identified is pregnancy, because this procedure includes radiography of the lumbopelvic region and thereby incurs a risk for the fetus.

\section{Benefits}

By the use of radiography and heel lift to delineate and correct unlevelness of the sacral base, one can reduce mild lumbar scoliosis in adults by approximately one third. This conclusion is contradistinctive to the assertion by Cailliet $^{13}$ that less than ${ }^{3 / 4}$-inch obliquity of the pelvis, measured by physical examination, is not significant for patients with scoliosis.

On the average, although the lateral bend of the lumbar spine was significantly reduced after leveling, the majority of the bend remained. This fact indicates that one or more factors (cofactors) in addition to the unlevelness of the sacral base have bearing on the reducibility of scoliosis.

Finally, an importance of the current study relative to the present classification of idiopathic scoliosis is that scoliosis reduced after leveling of the sacral base can be classified as postural in origin, rather than idiopathic.

Of interest for future study is the effect of sacral base leveling on such aspects as the at- 
titude of the thoracic vertebrae, the sacral base from the lateral view, and the lumbar spine with an angle of lateral bend $>20$ degrees.

Also of interest is whether other maladies associated with abnormal posture can be reduced or prevented by leveling the sacral base. ${ }^{21}$ Examples of maladies modulated by postural stress include costoclavicular compression with secondary cervical nerve entrapment, ${ }^{31}$ osteoarthritis, ${ }^{21}$ and low back syndrome. ${ }^{15}$

This work was supported in part by American Osteopathic Association Research grants No. 85-11190 and 86-11-190; Texas College of Osteopathic Medicine Organized Research grant 34100 ; and $\mathrm{Col}$ lege of Osteopathic Medicine of Oklahoma State University intramural grant.

The author thanks J. Kemplin, DO, and F.M. Wilkins, $D O$, for performance of radiographic measurements; J. Gramer, DO, for clinical consultation; and M. Emmett-Oglesby, PhD; J. Ellis, PhD; P. Greenman, DO; S. Irvin, DO; S. Leifheit, DO; and P. Stern, $D O$, for editorial assistance. The author also acknowledges the technical assistance of $D$. Anderson, PhD, S. Anderson, DO; E. Barnes; R. Barnes, $R T$; S. Carpenter, DO; J. Davis, LVN; E. Garrison; A. George; E. Griffin; A. Hade, DO; J. Hearne; A. Hood; D. Manuele, DO; J. Malone, RT; M. Parish, $D O$; and L. Sharatt, $D O$.

1. Fryette HH: Principles of Osteopathic Technique. Carmel, Calif, Academy of Applied Osteopathy, 1954, p 68.

2. Pope MH, Stokes IAF, Moreland M: Biomechanics of scoliosis. CRC Crit Rev Biomed Eng 11 (Issue 3);157-188.

3. Irvin RE: Evaluation of short leg syndrome in prevention of structural instability. Paper presented to the American Osteopathic College of Rheumatology, AOA 86th Annual Convention and Seminar, Nov 18, 1981, Los Angeles.

4. Grundy PF, Roberts CJ: Does unequal leg length cause back pain? A case-control study. Lancet 1984;2:256-258.

5. Mullen W: Choreia: Pindar and Dance. Princeton, NJ, Princeton University Press, 1982, p 67.

6. Patriquin DA: Lift therapy: A study of results. JAOA 1964;63:840-844.

7. Heilig D: Principles of lift therapy. JAOA 1978;77:466-472.

8. Beal M: The short leg problem. JAOA 1977;76:745-751.
9. Hilton J: Rest and Pain, ed 6. Philadelphia, JB Lippincott Co, 1950, p404.

10. Cailliet R: Low Back Pain Syndrome, ed 2. Philadelphia, FA Davis Co, 1979, p 52.

11. Schwab WA: Principles of manipulative treatment: The low back problem: XV. Statistics and summary JAOA 1934;33:286288.

12. Winter RB, Pinto WC: Pelvic obliquity: Its causes and its treatment. Spine 1986;11:225-234.

13. Cailliet R: Scoliosis: Diagnosis and Management. Philadelphia, FA Davis Co, 1980, pp 36-49.

14. Kraus ER: Postural roentgen study: A review of 16 years' experience. JAOA 1949;48:231-235.

15. Greenman P: Lift therapy: Use and abuse. JAOA 1979;79:238-250.

16. Tilley P: Radiographic identification of the sacral base. JAOA 1966;65:1177-1183.

17. Bailey H, Beckwith CG: Short leg and spinal anomalies: Their incidence and effects on spinal mechanics. JAOA 1937;36:319-327.

18. Pearson W: Progressive structural study of school children: An eight-year study of children in the rural areas of Adair County, Missouri. JAOA 1951;51:155-167.

19. Hagen DP: A continuing roentgenograpic study of rural school children over a 15-year period. JAOA 1964;63:546-557.

20. Denslow JS, Chace JA, Gutensohn OR: Methods in taking and interpreting weight-bearing x-ray films JAOA 1955;54:663670 .

21. Irvin RE: Postural balancing: A protocol for the routine reversal of chronic somatic dysfunction, abstrated. JAOA 1986;86:608.

22. Gracovetsky S, Farfan H: The optimum spine. Spine 1986;11:543-573.

23. Beilke MC: Simple mechanics of the sacrolumbar group JAOA 1939;39:165-167.

24. Meschan I: Roentgen Signs in Clinical Diagnosis. Philadelphia, WB Saunders Co, 1956, p 51.

25. Guyton AC: Textbook of Medical Physiology. Philadelphia, WB Saunders Co, 1976, p 1060.

26. Lyod P: Roentgenographic postural examination of the lumbar spine and pelvis. Read before the College of Osteopathic Surgeons, 1934.

27. Dvořák J, Dvořák V: Manual Medicine: Diagnostics. New York, Thieme Stratton Inc, 1984, pp 1-123.

28. Greenman P: Principles of Manual Medicine. Baltimore, Williams \& Wilkins, 1989, pp 1-352.

29. Schneider W, Dvořák J, Dvořák V: Manual Medicine: Therapy. New York, Thieme Medical Publishers, 1988, pp 1-148.

30. Sevastikoglou JA, Berquist E: Evaluation of the reliability of radiological methods for registration of scoliosis. Acta Orthop Scand 1969;40:608-613.

31. Hart FD (ed): French's Index of Differential Diagnosis, ed 10. Chicago, Year Book Medical Publishers Inc, 1976, p 560. 